\title{
Androgen generation in adipose tissue in women with simple obesity - a site-specific role for $17 \beta$-hydroxysteroid dehydrogenase type 5
}

\author{
Marcus Quinkler, Binayak Sinha, Jeremy W Tomlinson, \\ Iwona J Bujalska, Paul M Stewart and Wiebke Arlt \\ Division of Medical Sciences, University of Birmingham, Queen Elizabeth Hospital, Birmingham B15 2TH, United Kingdom \\ (Requests for offprints should be addressed to P M Stewart; Email: p.m.stewart@bham.ac.uk)
}

\begin{abstract}
Women with polycystic ovary syndrome (PCOS) have high circulating androgens, thought to originate from ovaries and adrenals, and frequently suffer from the metabolic syndrome including obesity. However, serum androgens are positively associated with body mass index (BMI) not only in PCOS, but also in simple obesity, suggesting androgen synthesis within adipose tissue. Thus we investigated androgen generation in human adipose tissue, including expression of $17 \beta$-hydroxysteroid dehydrogenase (17 $\beta-\mathrm{HSD})$ isozymes, important regulators of sex steroid metabolism. Paired omental and subcutaneous fat biopsies were obtained from 27 healthy women undergoing elective abdominal surgery (age range 30-50 years; BMI $19 \cdot 7-39 \cdot 2 \mathrm{~kg} / \mathrm{m}^{2}$ ). Enzymatic activity assays in preadipocyte proliferation cultures revealed efficient conversion of androstenedione to testosterone in both subcutaneous and omental fat. RT-PCR of whole fat and preadipocytes of subcutaneous and omental origin showed expression of $17 \beta-$ HSD types 4 and 5 , but no relevant expression of $17 \beta-H S D$ types 1,2 , or 3 . Microarray analysis confirmed this expression pattern $(17 \beta-H S D 5>17 \beta-H S D 4)$ and suggested a higher expression of $17 \beta-H S D 5$ in subcutaneous fat. Accordingly,
\end{abstract}

quantitative real-time RT-PCR showed significantly higher expression of $17 \beta-\mathrm{HSD} 5$ in subcutaneous compared with omental fat $(P<0 \cdot 05) .17 \beta-H S D 5$ expression in subcutaneous, but not omental, whole fat correlated significantly with BMI $(\mathrm{r}=0 \cdot 51, P<0 \cdot 05)$. In keeping with these findings, $17 \beta-$ HSD5 expression in subcutaneous fat biopsies from six women taking part in a weight loss study decreased significantly with weight loss $(P<0 \cdot 05)$. A role for $17 \beta-$ HSD 5 in adipocyte differentiation was further supported by the observed increase in $17 \beta-H S D 5$ expression upon differentiation of stromal preadipocytes to mature adipocytes $(n=5 ; \quad P<0 \cdot 005)$, which again was higher in cells of subcutaneous origin. Functional activity of $17 \beta-H S D 5$ also significantly increased with differentiation, revealing a net gain in androgen activation (androstenedione to testosterone) in subcutaneous cultures, contrasting with a net gain in androgen inactivation (testosterone to androstenedione) in omental cultures. Thus, human adipose tissue is capable of active androgen synthesis catalysed by $17 \beta-$ HSD 5 , and increased expression in obesity may contribute to circulating androgen excess.

Journal of Endocrinology (2004) 183, 331-342

\section{Introduction}

Hyperandrogenaemia is the principal biochemical finding in the polycystic ovary syndrome (PCOS) (Dunaif \& Thomas 2001). In addition, women with PCOS frequently present with obesity and have an increased risk of developing the metabolic syndrome including type 2 diabetes mellitus and hypertension (Dunaif \& Thomas 2001, Elting et al. 2001). High circulating androgens in PCOS have been thought to originate from increased androgen generation in ovaries and adrenals (Franks 1995). However, there is evidence for a significant contribution of peripheral steroidogenesis to androgen synthesis and activation in PCOS (Stewart et al. 1990, Fassnacht et al. 2003). Interestingly, serum androgens are positively associated with body mass index (BMI) not only in PCOS, but also in women with simple obesity (Taponen et al. 2003). This, together with a fall in luteinising hormone levels with increasing BMI (Holte et al. 1994), suggests that androgen synthesis may take place not only in adrenals and ovaries but also in adipose tissue.

Recent research focused on sex steroid conversion in human adipose tissue, specifically investigating the expression and activity of $17 \beta$-hydroxysteroid dehydrogenases (17 $\beta$-HSDs), which represent a major switch regulating sex steroid activation and inactivation at the pre-receptor 
level (Adamski \& Jakob 2001, Luu-The 2001). By employing RNA protection assays and Southern blot, Corbould et al. (1998) detected low mRNA expression levels of $17 \beta-$ HSD isozymes 2 and 3 , but not of $17 \beta-$ HSD1, in human adipose tissue. In another study, Corbould et al. (2002) found that preadipocytes readily converted androstenedione to testosterone and that the ratio of $17 \beta-\mathrm{HSD} 3$ to aromatase expression in omental adipose tissue was positively correlated with BMI. However, in recent years 17 $\beta$-HSD5 (AKR1C3) has been described as a major player in androgen interconversion (Dufort et al. 1999, Penning et al. 2000, Luu-The et al. 2001). Recently, Blouin et al. (2003) described mRNA expression of 17 $\beta$-HSD5 (AKR1C3) and 3 $\alpha$-HSD type 3 (AKR1C2) in human female adipose tissue. They reported an increased inactivation of $5 \alpha$-dihydrotestosterone by AKR1C2 in omental fat tissue from women with visceral obesity and suggested that local androgen inactivation is a predominant reaction in female abdominal tissue.

Here, we studied androgen generation in human female adipose tissue, particularly focusing on the site-specific expression of $17 \beta-H S D 5$ (AKR1C3) in omental and subcutaneous fat, and investigated the impact of changes in BMI. In addition, we explored 17 $\beta$-HSD5 expression and androgen conversion across adipocyte differentiation.

\section{Subjects and Methods}

\section{Subjects}

Paired subcutaneous and omental biopsies Paired subcutaneous (sc) and omental (om) adipose tissue biopsies were obtained from 27 female patients undergoing elective abdominal hysterectomy for myoma or fibroma (median age 43 years, range $30-50$ years; median BMI $27 \cdot 8 \mathrm{~kg} / \mathrm{m}^{2}$, range $19 \cdot 7-39 \cdot 2 \mathrm{~kg} / \mathrm{m}^{2}$ ). All were premenopausal, nondiabetic, and none of them had been treated with glucocorticoids within the preceding twelve months or had been on any hormonal treatment, e.g. contraceptives. In 24 of the 27 subjects sufficient material for both activity and expression studies was obtained, while biopsy material in the remaining three subjects was only sufficient for expression analysis.

Subcutaneous biopsies (weight loss study) Six healthy women (median age 45 years, range 23-57 years; median BMI $35 \cdot 2 \mathrm{~kg} / \mathrm{m}^{2}$, range $30 \cdot 4-38 \cdot 3 \mathrm{~kg} / \mathrm{m}^{2}$ ) with no significant past medical history were recruited for a weight loss study as previously reported (Tomlinson et al. 2004). A sc buttock biopsy was performed under local anaesthetic to obtain 1-2 $\mathrm{g}$ adipose tissue. After a median duration of 10 weeks of a weight loss program with a very low calorie diet $(425 \mathrm{kcal} /$ day) and a weight loss of more than $10 \%$ of the initial body weight, the patients returned to a normal
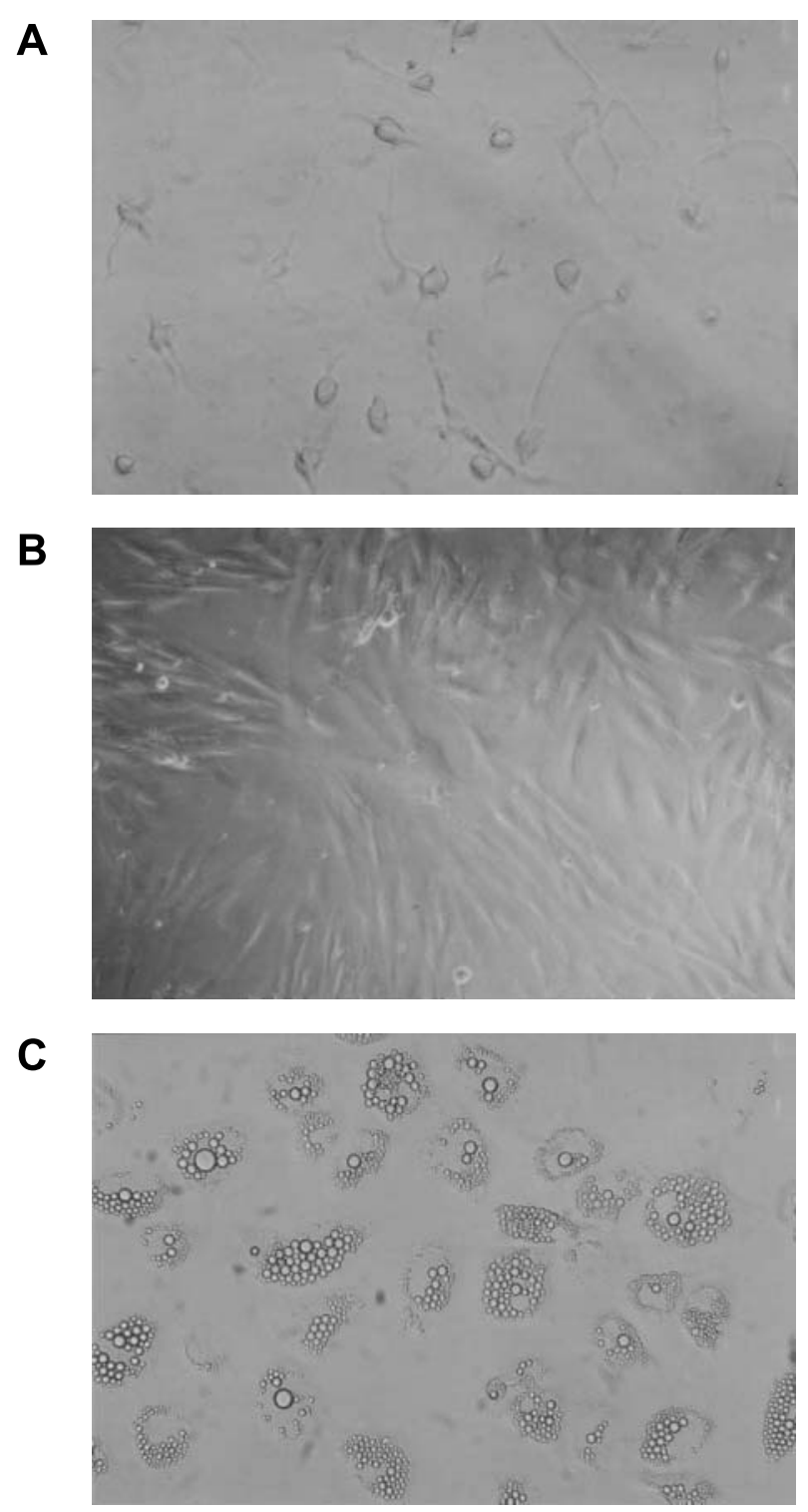

Figure 1 Human primary preadipocyte cell cultures. (A) Stromal preadipocytes on day $1,(\mathrm{~B})$ proliferation cultures with confluent preadipocytes on day $7,(\mathrm{C})$ differentiation cultures with preadipocytes fully differentiated into mature adipocytes (day 14). Magnification $\times 200$.

diet for at least 1 week before they received a second sc buttock biopsy (Tomlinson et al. 2004).

All studies had the approval of the local research ethics committee and written informed consent was obtained in every case.

\section{Tissue and primary cell culture}

Samples of whole sc and om fat tissue were used for RNA extraction and for the isolation of preadipocytes as previously reported (Bujalska et al. 1997). Briefly, adipose 

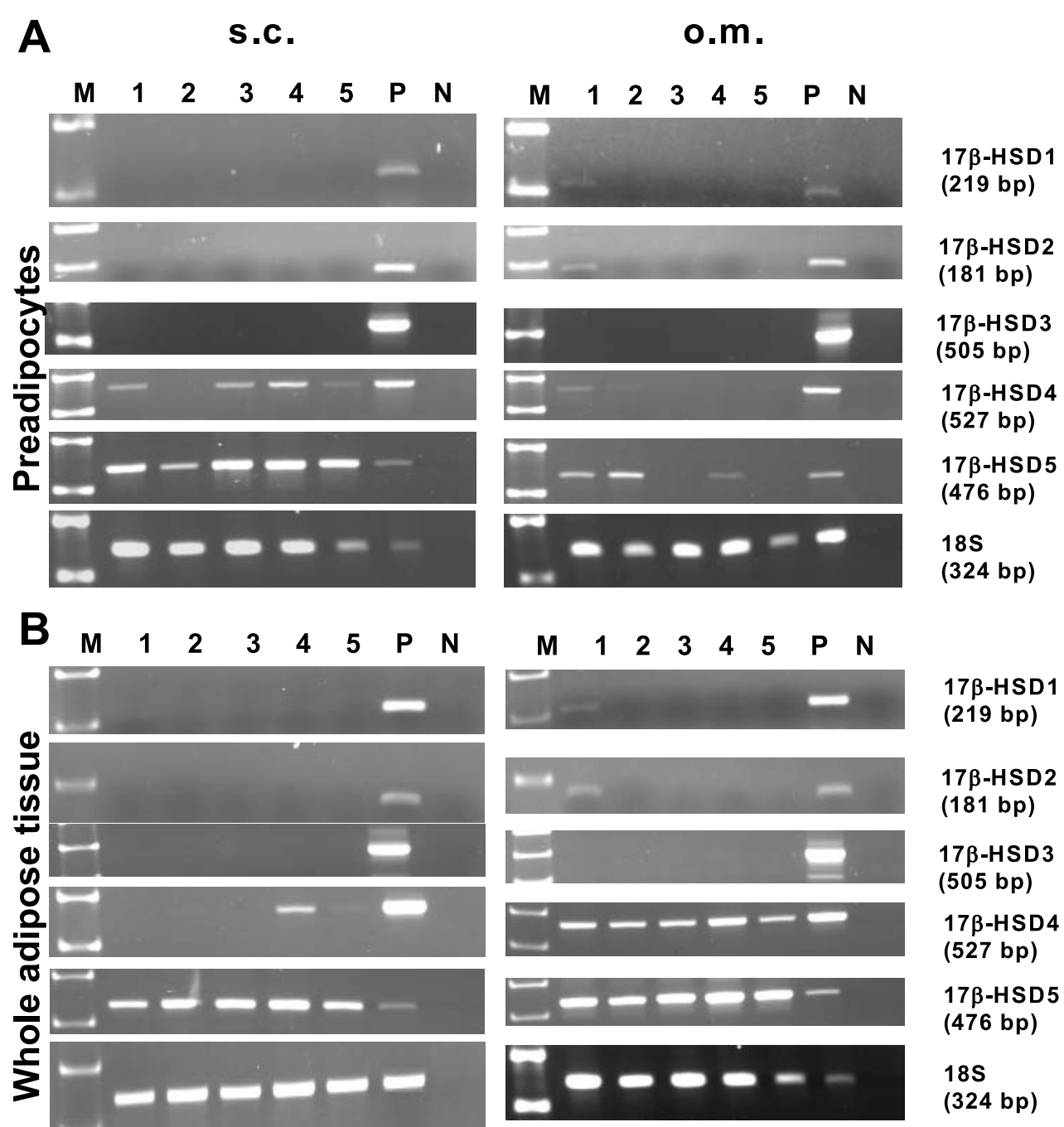

Figure 2 PCR analysis of $17 \beta$-HSD isozyme expression in subcutaneous (sc) and omental (om) preadipocytes (A) and whole fat tissue (B) RNA extracted from five women undergoing paired sc and om biopsies (1-5). M, ladder; $\mathrm{P}$, positive control (human testis for 17 $\beta$-HSD isoforms 1,3 and 4 ; human liver for $17 \beta$-HSDs 2 and 5); N, negative control; 18S, 18 S ribosomal RNA as internal loading control.

tissue biopsies were washed in PBS, then chopped and digested with collagenase class $1(2 \mathrm{mg} / \mathrm{ml}$; Worthington Biochemical Corp., Reading, Berks, UK) in $1 \times$ Hank's balanced salt solution (Life Technologies Inc., Paisley, Strathclyde, UK) for $60 \mathrm{~min}$ at $37^{\circ} \mathrm{C}$ in a shaking water bath. Samples were centrifuged at $90 \times \boldsymbol{g}$ for $1 \mathrm{~min}$, the top adipocyte layer was removed and then centrifuged again at $90 \times g$ for $5 \mathrm{~min}$. The pellet containing preadipocytes was removed, and cells were washed with DMEM/Nutrient Mixture F-12 (Life Technologies Inc.) containing 15\% fetal calf serum (Life Technologies Inc.), penicillin $(50000 \mathrm{U} / \mathrm{l})$ and streptomycin $(50000 \mu \mathrm{g} / \mathrm{l})$, and seeded in 24-well plates. Cells were left overnight and washed the following day with $1 \times$ Hank's balanced salt solution (Fig. 1A). Subsequently, preadipocyte cultures were either cultured towards confluence to study proliferated preadipocytes or subjected to differentiation stimuli to study the effects of maturation of stromal preadipocytes to adipocytes.

For preadipocyte proliferation cultures, human preadipocytes were maintained in DMEM/F-12 medium containing 15\% fetal calf serum until confluence, which was achieved after 5 and 7 days of cell culture (Fig. 1B). Preadipocytes were then used for enzyme assays and RNA extraction.

For preadipocyte differentiation assays, human subcutaneous and omental preadipocytes were cultured for 14 days in media known to promote adipocyte differentiation (Hauner et al. 1987) following an established protocol (Bujalska et al. 1999) (Fig. 1C). On days 1 and 14, 
Table 1 Expression of $17 \beta-H S D$ isozymes according to cDNA arrays with RNA extracted from preadipocytes and whole fat tissue of both subcutaneous (sc) and omental (om) origin. For each cell compartment the corresponding specific RNAs of 5 women were pooled

\begin{tabular}{|c|c|c|c|c|c|}
\hline & \multicolumn{2}{|c|}{ Subcutaneous } & \multicolumn{2}{|l|}{ Omental } & \multirow{2}{*}{$\begin{array}{l}\text { Fold } \\
\text { change } \\
\text { sc vs om }\end{array}$} \\
\hline & Detection & Signal & Detection & Signal & \\
\hline \multicolumn{6}{|l|}{$\begin{array}{l}\text { Enzyme } \\
\text { (Gene) }\end{array}$} \\
\hline \multicolumn{6}{|l|}{ Preadipocytes } \\
\hline $\begin{array}{l}\text { 17ß-HSD1 } \\
\text { (HSD17B1) }\end{array}$ & A & - & A & - & - \\
\hline $\begin{array}{l}\text { 17ß-HSD2 } \\
\text { (HSD17B2) }\end{array}$ & A & - & A & - & - \\
\hline $\begin{array}{l}\text { 17ß-HSD3 } \\
\text { (HSD17B3) }\end{array}$ & A & - & A & - & - \\
\hline $\begin{array}{l}\text { 17ß-HSD4 } \\
\text { (HSD17B4) }\end{array}$ & $\mathrm{P}$ & 263 & $\mathrm{P}$ & 222 & - \\
\hline $\begin{array}{l}\text { 17ß-HSD5 } \\
\text { (AKR1C3) }\end{array}$ & $\mathrm{P}$ & 511 & $\mathrm{P}$ & 73 & $6 \cdot 5$ \\
\hline \multicolumn{6}{|c|}{ Whole fat tissue } \\
\hline $\begin{array}{l}\text { 17ß-HSD1 } \\
\text { (HSD17B1) }\end{array}$ & A & - & A & - & - \\
\hline $\begin{array}{l}\text { 17ß-HSD2 } \\
\text { (HSD17B2) }\end{array}$ & A & - & A & - & - \\
\hline $\begin{array}{l}\text { 17ß-HSD3 } \\
\text { (HSD17B3) }\end{array}$ & A & - & A & - & - \\
\hline $\begin{array}{l}\text { 17ß-HSD4 } \\
\text { (HSD17B4) }\end{array}$ & $\mathrm{P}$ & 330 & $\mathrm{P}$ & 303 & - \\
\hline $\begin{array}{l}\text { 17ß-HSD5 } \\
\text { (AKR1C3) }\end{array}$ & $\mathrm{P}$ & 1525 & $\mathrm{P}$ & 428 & $3 \cdot 4$ \\
\hline
\end{tabular}

Detection: qualitative measure indicating if the transcript is reliably detected (present, P), not detected (absent, A). Signal: quantitative measure of the relative abundance of a transcript. Fold change: change in expression level for a transcript between sc and om.

total RNA was extracted and differentiation of adipose stromal cells to adipocytes was confirmed by analysing lipoprotein lipase and glycerol-3-phosphate dehydrogenase expression, as described previously (Bujalska et al. 2002b). In addition, sc and om preadipocyte cultures were used for enzymatic activity assays on day 1 and day 14 of differentiation.

\section{Enzyme assays}

Paired sc and om preadipocyte proliferation cultures from 19 women were incubated in serum-free DMEM without phenol for $20 \mathrm{~h}$ with $40 \mathrm{nM}$ androstenedione containing 100000 c.p.m. $\left[1,2,6,7-{ }^{3} \mathrm{H}\right]$ androstenedione (specific activity $25 \mathrm{Ci} / \mathrm{mmol}$; Perkin-Elmer, Cambridge, Cambs, UK).

Paired sc and om preadipocyte differentiation cultures from 5 women were incubated on day 1 and day 14 in serum-free DMEM without phenol for $20 \mathrm{~h}$ with $40 \mathrm{nM}$ androstenedione containing 100000 c.p.m. $\left[1,2,6,7-{ }^{3} \mathrm{H}\right]$ androstenedione or with $40 \mathrm{nM}$ testosterone containing 100000 c.p.m. $\left[1,2,6,7{ }^{3} \mathrm{H}\right]$ testosterone (specific activity $78 \cdot 5 \mathrm{Ci} / \mathrm{mmol}$; Perkin-Elmer).
Steroids were extracted in 5 vols dichloromethane, concentrated by evaporation, and separated by thin layer chromatography (TLC) on silica gel/aluminium foilcoated TLC plates (Fluka Chemika, Buchs, Switzerland) with chloroform/ethylacetate (80:20) as the solvent system. Fractional conversion of steroids was quantified using a Bioscan 2000 Imager (LabLogic, Sheffield, UK). Steroids were identified by referring to co-migration of unlabelled steroid standards (Sigma, UK) visualised by LiebermannBurchard reagent as previously described (Quinkler et al. 1999). Cell protein content was determined with a modified Bradford method (Bio-Rad Laboratories, Munich, Germany), and enzyme activities were expressed as pmol or fmol product formed per mg protein per h. All incubations were carried out at least in triplicate.

\section{$R N A$ extraction and $R T$}

Total RNA was extracted from whole fat tissue and preadipocyte cultures using a single step extraction method (Tri reagent, Sigma, UK (preadipocytes), or Genelute total mammalian RNA extraction kit, Sigma, UK (whole adipose tissue)). RNA integrity was assessed by gel 


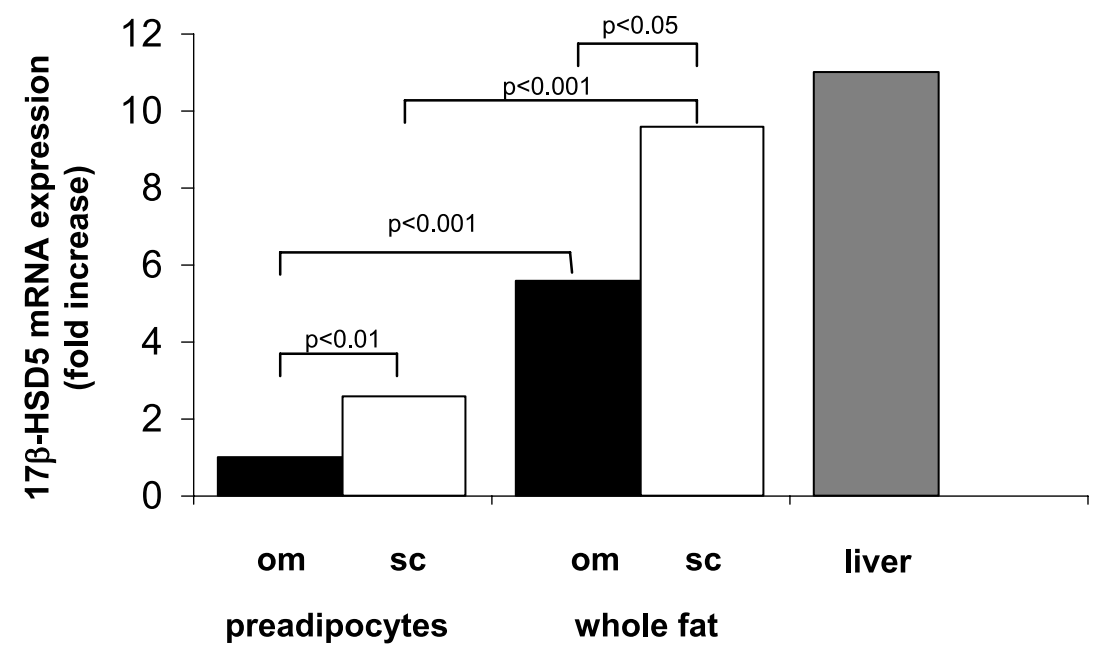

$\begin{array}{crrrrr}\text { Mean dCT } & 13.95 & 12.59 & 11.47 & 10.69 & 10.46 \\ \pm \text { SD } & 1.09 & 1.31 & 1.02 & 1.40 & 0.20\end{array}$

Figure 3 Quantitative mRNA expression of $17 \beta$-HSD 5 according to real-time PCR in omental (om) and subcutanous (sc) preadipocytes and whole fat of 19 women, and in liver ( 3 women). Expression in om preadipocytes was set at 1 and other expressions were compared with it as fold increase. Mean $\Delta \mathrm{CT}(\mathrm{dCT})$ is shown beneath the graphs.

electrophoresis and concentrations were measured by spectrophotometry at $A_{260}$ and checked for purity using the ratio $A_{260 / 280}$. Reverse transcription of RNA was performed as previously described (Bujalska et al. 1999) employing reagents from Promega (Southampton, UK).

\section{PCR for $17 \beta$-HSD isozymes}

Qualitative PCR analysis for expression of $17 \beta-$ HSD isozymes was carried out using cDNA generated from paired sc and om fat samples of 5 women, employing the following primers: 17 $\beta-H S D 1$ (HSD17B1), forward: 5'-TTTCA ATGACGTTTATTGCGCCAGCA-3', reverse: $5^{\prime}$-TTG CTGTGGGCGAGGTATTGGTAGAA-3'; 17 $\beta$-HSD2 (HSD17B2), forward: 5'-CTGGTGACAGGTGGTGA

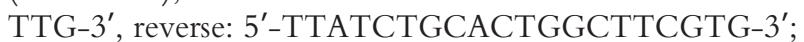
17 $\beta$-HSD3 (HSD17B3), forward: 5'-TCCTGAACGCA CCGGATGAAAT-3', reverse: 5'-TACCTGACCTTG GTGTTGAGCTTCAG-3'; 17 $\beta$-HSD4 (HSD17B4), forward: 5'-AGTTCTCTCTCTTTCTTGTTGGCTC TGGA-3', reverse: 5'-GCGTCCTATTTCCTCAAA TACAAAGGTACTCT-3'; 17 $\beta$-HSD5 (AKR1C3), forward: 5 '-ACTTCATGCCTGTATTGGGATTTG-3', reverse: 5 '-CTGCCTGCGGTT $\overline{G A}$ AGTTTGACA-3'. $17 \beta$-HSD 5 primers differ in two bases (forward primer) and three bases (reverse primer) respectively, from the AKR1C2 sequence (see underlined bases above) and are specific for 17 $\beta$-HSD5 (AKR1C3) as previously shown by Bumke-Vogt et al. (2002). In addition to the primer sequences for $17 \beta-H S D$ isozymes 1,2 , and 3 given above, we also performed specific PCR reactions with the $17 \beta-H S D$ primers used by Corbould et al. (1998). Specific PCR reactions $(20 \mu \mathrm{l})$ were carried out in $1 \times$ PCR buffer (Promega) containing $50 \mathrm{mM} \mathrm{KCl}, 10 \mathrm{mM}$ Tris- $\mathrm{HCl}(\mathrm{pH}$ 9.0), and $0 \cdot 1 \%$ Triton $\mathrm{X}-100,2 \mathrm{mM} \mathrm{MgCl}_{2}, 0 \cdot 2 \mu \mathrm{M}$ of each dNTP, $0.6 \mu \mathrm{M}$ of forward and reverse primer and 1 U Taq DNA polymerase (Promega). Samples were amplified using initial denaturation at $94{ }^{\circ} \mathrm{C}(5 \mathrm{~min})$ followed by 34 cycles at $94{ }^{\circ} \mathrm{C}(30 \mathrm{~s}), 60{ }^{\circ} \mathrm{C}(30 \mathrm{~s})$, and $72{ }^{\circ} \mathrm{C}$ (30 s) with final elongation at $72{ }^{\circ} \mathrm{C}(7 \mathrm{~min})$. After gel electrophoresis, PCR products of reactions with $17 \beta$ HSD5 primers were excised under UV light, extracted with QIAquick Gel Extraction Kit (Qiagen) and subjected to direct sequencing.

\section{Microarray}

Total RNA was extracted from paired sc and om whole fat tissue as well as from preadipocyte proliferation cultures from five women. Biotin-labelled cRNA was reverse transcribed from $10 \mu \mathrm{g}$ total RNA (pool of $2 \mu \mathrm{g}$ total RNA from each cell preparation) according to the Affymetrix technical protocol (GeneChip Expression Analysis, Technical Manual, http://www.affymetrix.com/support/ index.affx). Integrity of the samples was tested on Affymetrix Test3 array and samples were accepted if their $3^{\prime} / 5^{\prime}$ ratio of human housekeeping genes was lower than 3, referring to the house-keeping genes betaactin (ACTB, Affymetrix probe HSAC07/X00351) and glyceraldehyde-3-phosphate dehydrogenase (GAPD, 


\section{A}

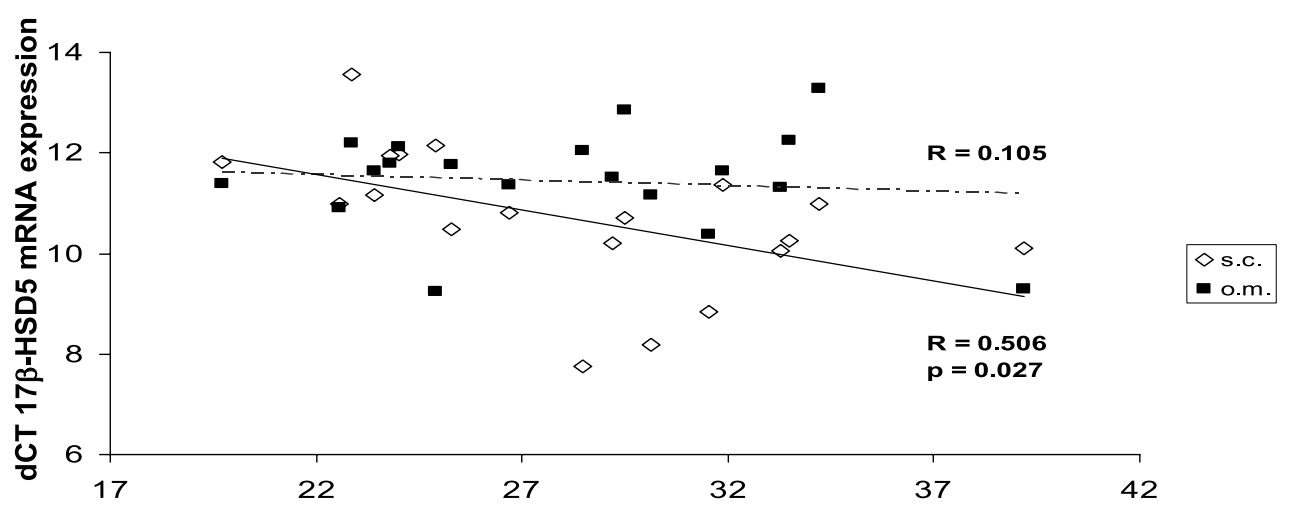

BMI

\section{B}

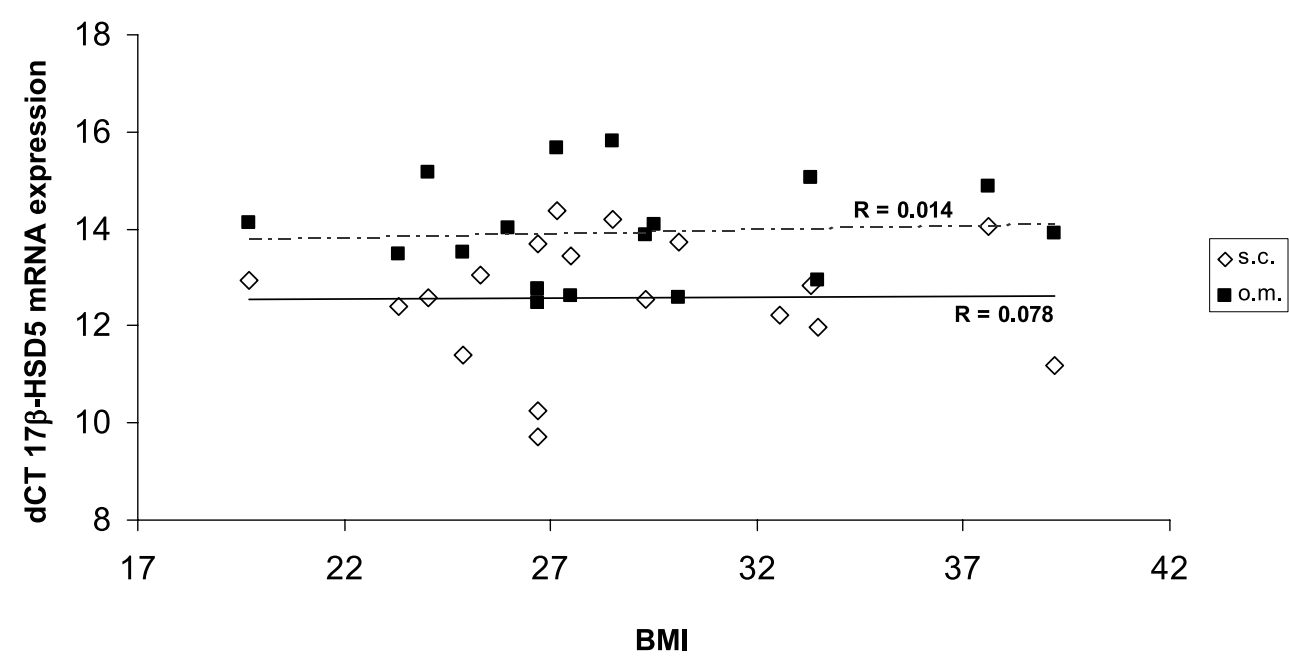

Figure 4 Quantitative mRNA expression of $17 \beta$-HSD5 according to real-time PCR reported as $\triangle C T(d C T)$ values (high values represent low values of expression) in correlation to body mass index (BMI) in 19 women. (A) Expression in omental $(\mathrm{om}, \mathbf{\square})$ and subcutanous $(\mathrm{sc}, \diamond)$ whole fat. (B) Expression in om and sc $(\diamond)$ preadipocytes.

Affymetrix probe HUMGAPDH/M33197) were accepted. Fragmented cRNA $(15 \mu \mathrm{g})$ was hybridised to each of the array of the Human Genome U133 set (Affymetrix, High Wycombe, UK). Affymetrix software (Data Mining Tool, Version 3.0) and Microarray Data Suite 5.0 (Affymetrix) were used for analysing microarray data. Accordingly, results are presented as qualitative (=detection) and quantitative (=signal) measures of expression level, which represent arbitrary data. The inter-assay variability be- tween microarrays was below 5\%. The probe set for 17 $\beta$-HSD5 (209160_at) on the HG U133A chip includes 11 probes, all matching the published sequence. Due to the sequence difference between 17 $\beta$-HSD5 and other $17 \beta-$ HSD enzymes, none of the probes coding for $17 \beta$ HSD 5 match the probe sets of $17 \beta$-HSD isozymes $1,2,3$ or 4. The enzymes AKR1C1 (probe set 204151_x_at) and AKR1C2 (probe set 209699_x_at) have a high homology to $17 \beta$-HSD5 (AKR1C3); however only 2 and 3 probes, 
respectively, out of 11 probes matched the $17 \beta-\mathrm{HSD} 5$ sequence.

\section{Quantitative PCR}

17 $\beta$-HSD 5 mRNA expression was analysed using an ABI Prism 7700 sequence detection system (Perkin-Elmer Applied Biosystems, Warrington, UK) that employs TaqMan chemistry for highly accurate mRNA quantification as previously described (Bujalska et al. 2002a). Reactions were performed in 25- $\mu \mathrm{l}$ vol on 96-well plates, in buffer containing TaqMan Universal PCR Master Mix (Applied Biosystems, Foster City, CA, USA) and $25 \mathrm{ng}$ cDNA template. All reactions were multiplexed with the housekeeping gene $18 \mathrm{~S}$ (Perkin-Elmer). Reactions were as follows: $50{ }^{\circ} \mathrm{C}$ for $2 \mathrm{~min}, 95^{\circ} \mathrm{C}$ for $10 \mathrm{~min}$, and then 44 cycles at $95^{\circ} \mathrm{C}$ for $15 \mathrm{~s}$ and $60{ }^{\circ} \mathrm{C}$ for $1 \mathrm{~min}$. Oligonucleotide primers and a Taqman probe for $17 \beta-$ HSD 5 were as follows: forward, GGGATCTCAACGAGACAAACG; reverse, AAAGGACTGGGTCCTCCAAGA; probe, TGG ACCCGAACTCCCCGGTG. Data were expressed as CT values (= cycle number at which logarithmic PCR plots cross a calculated threshold line) and were used to determine $\Delta \mathrm{CT}$ values ( $=\mathrm{CT}$ of the target gene minus $\mathrm{CT}$ of the housekeeping gene; high $\Delta \mathrm{CT}$ values represent low levels of expression). Fold changes were calculated using transformation [fold increase $=2^{\text {-difference in } \Delta \mathrm{CT}}$ ].

\section{Statistical analysis}

Data are expressed as means \pm S.D or S.E.M., as specified. Statistical analysis on real-time PCR data was performed on mean $\Delta \mathrm{CT}$ values to exclude potential bias owing to averaging data that had been transformed through the equation $2^{-\Delta \mathrm{CT}}$. Statistical analysis of comparisons between groups was undertaken using paired and unpaired $t$-tests where appropriate, otherwise the Mann-Whitney Rank Sum Test was used. Linear regression analysis was performed using Pearson's correlation coefficient.

\section{Results}

\section{PCR for $17 \beta$-HSD isozymes}

The conversion of androstenedione to testosterone and vice versa requires the presence of reductive and oxidative $17 \beta-$ HSD activity. Thus, to identify the enzymes responsible for testosterone synthesis and inactivation in adipose tissue, we performed RT-PCR analysis employing specific primers for the amplification of human 17 $\beta$-HSD isozymes. When analysing preadipocyte and whole adipose mRNA obtained from sc and om depots of five individual patients, abundant expression of $17 \beta-$ HSD 4 and $17 \beta-$ HSD 5 mRNA was detected (Fig. 2). The data suggest that $17 \beta-$ HSD 4 expression is higher in om than

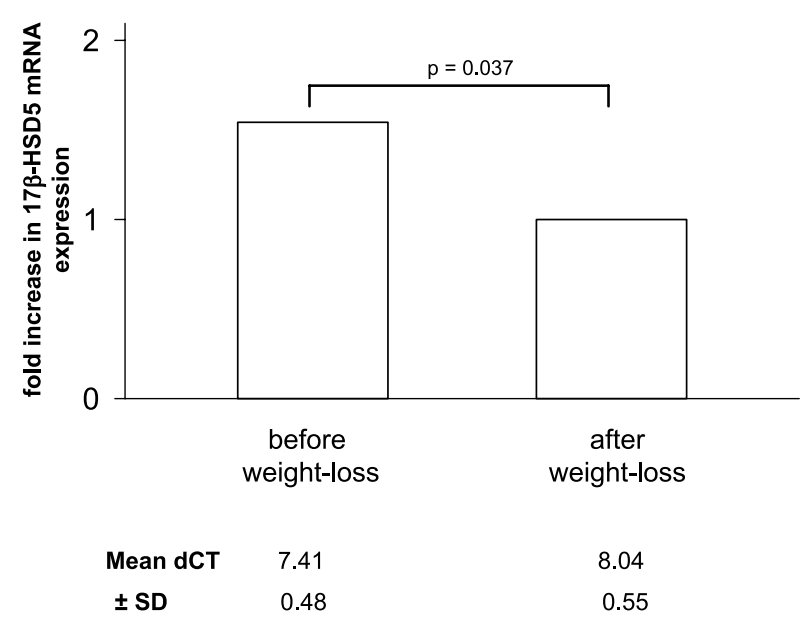

Figure 5 Quantitative mRNA expression of $17 \beta$-HSD5 according to real-time PCR in subcutaneous whole fat buttock biopsies from six women before and after weight loss, who underwent a weight loss study ( $>10 \%$ of initial body weight). Mean $\Delta C T(\mathrm{dCT})$ is shown beneath the graphs.

sc whole adipose tissue. $17 \beta-$ HSD 5 expression appears to be weakest in om preadipocytes. In whole fat and preadipocytes of both sc and om origin no relevant expression of $17 \beta-H S D 1,2$ or 3 was detected, except for a weak band for $17 \beta-$ HSD 1 and 2 in omental tissue of one subject (Fig. 2). Using the primers and methods reported by Corbould et al. (1998) we were not able to detect mRNA expression of $17 \beta-\mathrm{HSD}$ isozymes 1,2 or 3 , either in whole fat or in preadipocytes, despite a strong band in the positive control lane (data not shown).

\section{Microarray}

Microarray analysis confirmed the absence of $17 \beta-$ HSD1, 2 and 3 and the presence of $17 \beta-H S D 4$ and 5 in preadipocytes and whole fat tissue of $\mathrm{sc}$ and om origin (Table 1). 17 $\beta$-HSD5 microarray expression signals were higher in sc than in om fat (511 vs 73 in preadipocytes, $P<0 \cdot 001 ; 1525$ vs 428 in whole fat, $P<0 \cdot 001)$, with an apparently higher abundance in whole fat than in preadipocytes of sc origin. By contrast, $17 \beta-\mathrm{HSD} 4$ expression signals did not differ significantly between sc and om fat, either in preadipocytes (263 vs 222 ) or in whole fat tissue (330 vs 303). The expression levels of AKR1C1 and AKR1C2 were very high (2800 and 2200 respectively) and exceeded those of 17 $\beta$-HSD5 (AKR1C3) in whole fat tissue with no significant difference between sc or om tissue.

\section{Enzyme assays in preadipocyte proliferation cultures}

Enzyme activity studies in primary preadipocyte proliferation cultures from 19 patients revealed significant androgen generation, as assessed by the conversion of androstenedione to testosterone, with no apparent 


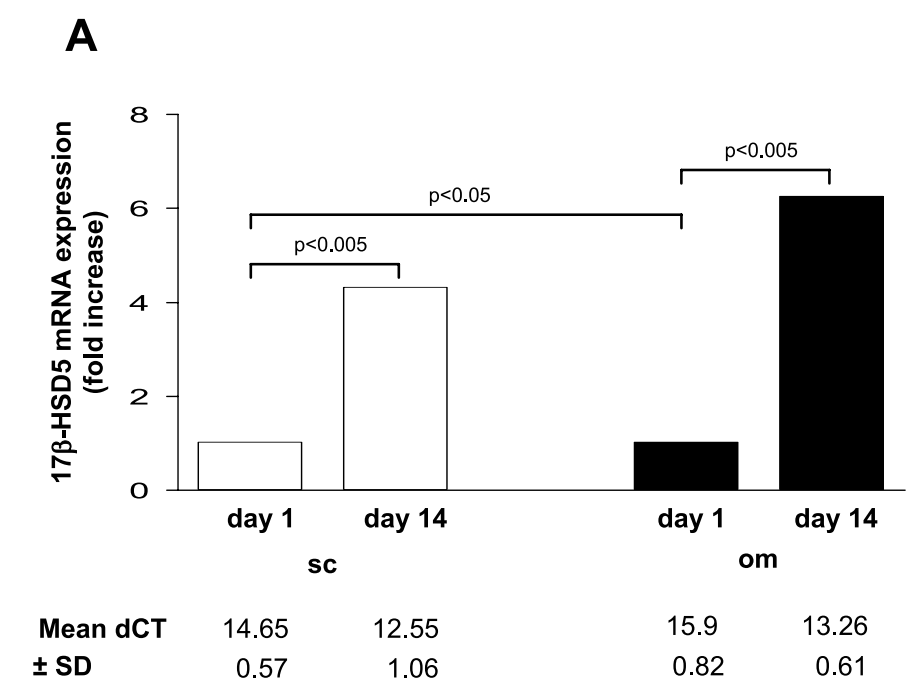

B

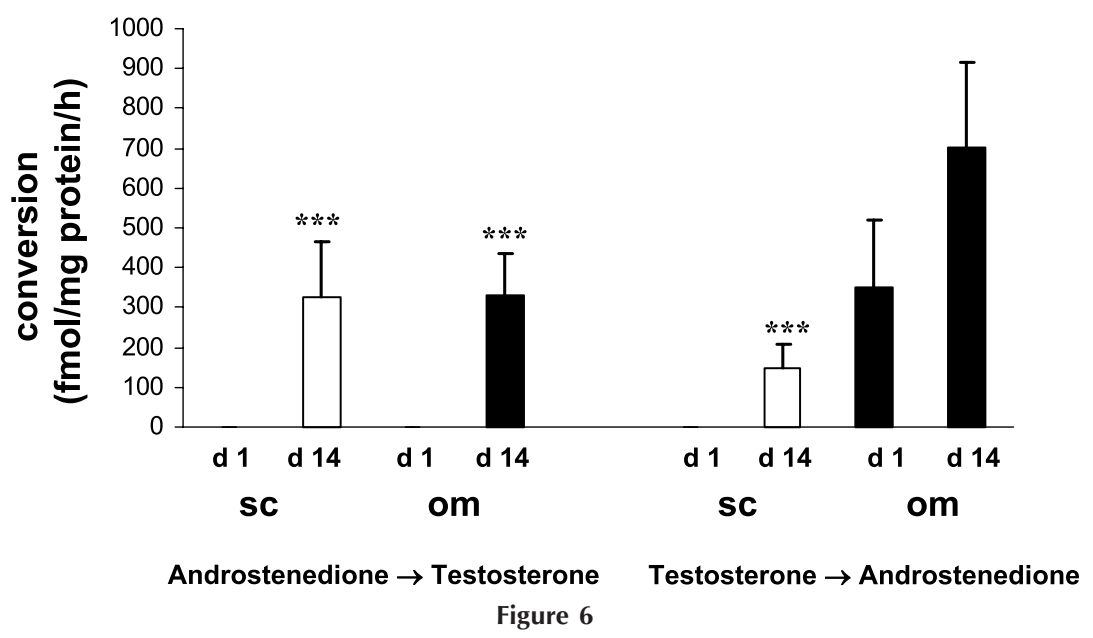

difference between sc and om preadipocyte cultures $(0 \cdot 83 \pm 0.24$ vs $0.86 \pm 0.23 \mathrm{pmol} / \mathrm{mg} / \mathrm{h})$.

Quantitative PCR for site-specific expression of 17ß-HSD5

For validation of the results on $17 \beta-$ HSD 5 expression in fat achieved by microarray analysis, we performed quantitative real-time PCR on cDNA generated from paired sc and om fat biopsies of 19 women. In keeping with the micorarray data, $17 \beta-$ HSD 5 mRNA expression levels were significantly higher in sc than in om fat, both in preadipocytes $(P<0 \cdot 01)$ and in whole fat $(P=0 \cdot 05)$ (Fig. 3). However, in both sc and om depots, $17 \beta-$ HSD 5 mRNA expression was significantly higher in whole fat tissue than in preadipocytes $(P<0 \cdot 001)$ (Fig. 3). This suggests a much higher abundance of $17 \beta-$ HSD5 expression in mature adipocytes than in preadipocytes.

A potential site-specific role for $17 \beta-H S D 5$, in the light of higher abundance of expression in sc than in om fat, was also supported by correlation of real-time $17 \beta-$ HSD 5 mRNA expression with BMI in the 19 patients studied (Fig. 4A and B). 17 $\beta$-HSD5 mRNA expression in whole adipose tissue was significantly correlated with BMI in the sc compartment $(\mathrm{r}=0.51, P=0.027)$ but not in the om $\operatorname{depot}(r=0 \cdot 11)$ (Fig. 4A). By contrast, expression of $17 \beta-$ HSD5 in preadipocytes, which was considerably lower than in whole fat tissue, did not correlate with BMI, either in cells of om $(r=0.078)$ or sc $(r=0 \cdot 014)$ origin (Fig 4B). There was no significant correlation between 17ß-HSD5 mRNA expression and age in whole fat or preadipocytes. 
C

\section{Testosterone $\rightarrow$ Androstenedione $\quad$ Androstenedione $\rightarrow$ Testosterone} om day 14

\section{om day 1}

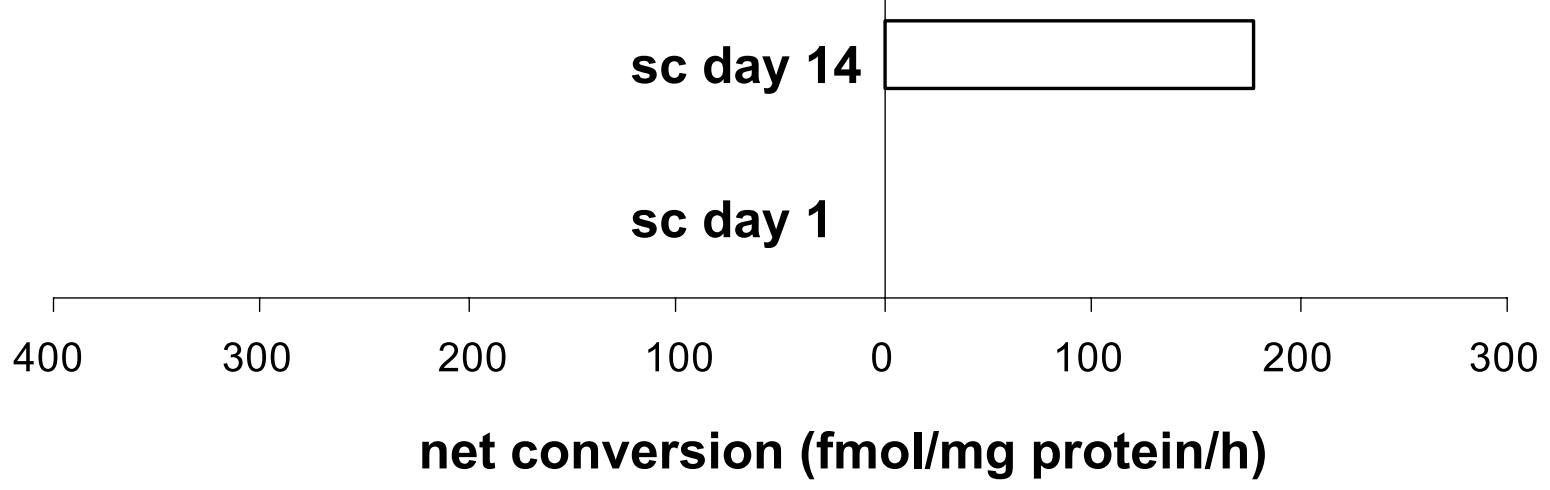

Figure 6 Continued.

Figure 6 Androgen conversion and quantitative mRNA expression of 17 $\beta$-HSD 5 across the differentiation of preadipocytes. (A) Quantitative mRNA expression of $17 \beta-$ HSD5 according to real-time PCR in omental (om) and subcutaneous (sc) preadipocytes before (day 1) and after (day 14) differentiation to adipocytes, reported as $\triangle \mathrm{CT}$ (dCT) values (high values represent low values of expression) $(n=8)$. (B) Conversion ( $\mathrm{fmol} / \mathrm{mg}$ protein $/ \mathrm{h}$ ) of androstenedione to testosterone and testosterone to androstenedione in om and sC preadipocytes before (day $1, \mathrm{~d} 1$ ) and after (day 14 , d14) differentiation to adipocytes $(n=5)$. Results are expressed as means \pm S.E.M. ${ }^{*} * \mathrm{P}<0.001$ comparing day 14 to day 1 . (C) Net conversion ( $\mathrm{fmol} / \mathrm{mg}$ protein/h) of testosterone to androstenedione and vice versa in om and Sc preadipocytes before (day 1 ) and after (day 14) differentiation to adipocytes.

Quantitative PCR for 17ß-HSD5 expression in weight loss study

We performed quantitative real-time PCR on cDNA generated from subcutaneous buttock biopsies of six women who underwent a weight loss study. The mRNA expression of $17 \beta-$ HSD5 was significantly reduced $(P<0 \cdot 05)$ in the biopsies taken after the weight loss compared with those taken before the weight loss (Fig. 5).

\section{Quantitative PCR for 17 $\beta$-HSD5 expression across} differentiation

To further explore the expression of $17 \beta-$ HSD 5 across differentiation, primary preadipocyte cultures from sc and om fat of eight individuals were differentiated to mature adipocytes in adipogenic medium. 17 $\beta$-HSD5 mRNA levels were assessed by real-time RT-PCR and again were found to be significantly higher $(P<0 \cdot 05)$ in sc than in om preadipocytes on day 1 . Upon differentiation to adipocytes (day 1 compared with day 14), 17 $\beta$-HSD5 mRNA levels in both om and sc cultures increased significantly $(P<0 \cdot 005)$ (Fig. 6A).

Enzyme assays in preadipocyte differentiation cultures

We studied the conversion of androstenedione to testosterone and vice versa across differentiation using primary preadipocyte differentiation cultures from $\mathrm{sc}$ and om fat of five women. On day 1 we could not detect any conversion of androstenedione to testosterone in sc and om preadipocytes (Fig. 6B). Omental, but not subcutaneous, preadipocytes readily converted testosterone to androstenedione on day 1. After differentiation to mature adipocytes on day 14 , om and sc cultures exhibited similar conversion rates of androstenedione to testosterone, whereas the reverse conversion of testosterone to androstenedione was much 
stronger in the om than in cultures of sc origin (Fig 6B). When calculating the net conversion in preadipocyte differentiation cultures, om preadipocytes predominantly inactivated testosterone to androstenedione both before (day 1) and after 14 days of differentiation (Fig. 6C). By contrast, in differentiated cells (day 14) of sc origin net conversion revealed a significant gain in androgen activation, i.e. conversion of androstenedione to testosterone (Fig. 6C).

\section{Discussion}

Conversion of androstenedione to testosterone in human adipose tissue may represent an intracrine source of androgen synthesis, possibly also contributing to the previously described positive correlation between circulating androgens and BMI (Taponen et al. 2003). It is important to recognize that this may follow a sex-specific pattern as this correlation has been found in women only (Taponen et al. 2003). Epidemiological studies have found that circulating levels of dehydroepiandrosterone (DHEA) sulphate, the sulphate ester of the crucial androgen precursor DHEA, are positively correlated with truncal fat in women (Williams et al. 1993) whilst there is an inverse correlation in men (Haffner et al. 1993). Thus androgen metabolism within male adipose tissue may differ from the pattern we report here in women.

Previous studies by Corbould et al. $(1998,2002)$ suggested that $17 \beta-H S D 3$, which primarily shows gonadal expression, is also expressed in female adipose tissue. They concluded that $17 \beta-$ HSD3 may be responsible for the conversion of androstenedione to testosterone, because no functional 17 $\beta$-HSD1 enzyme was found in adipose tissue (Corbould et al. 1998). However, we were not able to detect any $17 \beta-H S D 3$ mRNA expression in our fat tissue samples, even using the primers described by Corbould et al. and highly sensitive microarray techniques. There are some differences between the study presented by Corbould et al. (1998) and our study, in particular with regard to tissue handling and preadipocyte cultures. We have grown the preadipocytes in proliferation culture until confluence, i.e. for 5-7 days, before isolating RNA, whereas Corbould et al. used preadipocytes immediately after isolation and without further culturing. However, Corbould et al. did not investigate 17 $\beta$-HSD5 expression in their fat samples, which is a likely candidate enzyme for the catalysis of the conversion of androstenedione to testosterone (Dufort et al. 1999, El-Alfy et al. 1999, Qiu et al. 2004). Very recently, $17 \beta-H S D 5$ has been shown to be expressed in human adipose tissue (Blouin et al. 2003). We did not observe expression of $17 \beta-H S D 3$, but did define abundant expression of $17 \beta-H S D 5$. Thus we consider it highly likely that $17 \beta-$ HSD 5 represents the main reductive $17 \beta-\mathrm{HSD}$ isozyme responsible for conversion of androstenedione to testosterone in human fat. The only other $17 \beta-H S D$ enzyme we found to be expressed in adipose tissue was $17 \beta-$ HSD 4 , which only catalyses the oxidative reaction and therefore cannot convert androstenedione to testosterone (Adamski \& Jakob 2001, LuuThe 2001, Mindnich et al. 2004).

According to our microarray data and quantitative real-time PCR results comparing whole fat with preadipocytes, we found $17 \beta-\mathrm{HSD} 5$ to be predominantly expressed in mature adipocytes, suggesting a role for this enzyme in adipocyte differentiation (Singh et al. 2003). This is further supported by the outcome of our preadipocyte differentiation assays, which showed a significant increase in $17 \beta-H S D 5$ expression upon differentiation from stromal preadipocytes to mature adipocytes. However, it is not clear if the increased expression of $17 \beta-H S D 5$ represents cause or consequence of ongoing differentiation. The increase in intracrine generation of androgens via the conversion of androstenedione to testosterone may influence differentiation (Singh et al. 2003). 17 $\beta$-HSD5 also catalyses the conversion of DHEA to androstenediol, which has been shown to occur in female adipose tissue following incubation with radiolabelled DHEA (Schindler \& Aymar 1975). Androstenediol has very similar structural characteristics to $5 \alpha$-androstanediol, which recently has been shown to exhibit differentiating effects in the prostate via selective activation of the oestrogen receptor $\beta(\mathrm{ER} \beta$ ) (Weihua et al. 2002).

The results of the enzymatic activity assay in our preadipocyte differentiation cultures revealed predominant androgen inactivation, i.e. conversion of testosterone to androstenedione, which is likely to be be catalysed by $17 \beta-H S D 4$, as we did not detect expression of the other oxidative 17 $\beta$-HSD isozyme, 17 $\beta-H S D 2$. Blouin et al. (2003) previously suggested that omental adipose tissue represents an androgen inactivating rather than an androgen activating tissue. This is further supported by their finding of increased inactivation of $5 \alpha$-dihydrotestosterone by $3 \alpha-\mathrm{HSD}$ activity, possibly catalysed by AKR1C2 (Blouin et al. 2003).

In contrast to the predominant androgen inactivation in om cultures, calculation of net conversion in our preadipocyte differentiation cultures of sc origin revealed significant androgen activation, i.e. conversion of androstenedione to testosterone, suggesting that sc fat depots participate in systemic androgen production.

Our findings strongly suggest a site-specific role for $17 \beta-H S D 5$. First, $17 \beta-H S D 5$ expression was significantly higher in sc than in om adipose tissue. Secondly, we found a significant positive correlation of BMI with $17 \beta-H S D 5$ expression in sc, but not in om fat in our female cohort. Conversely, we could show that $10 \%$ weight loss resulted in a significant decrease in $17 \beta-H S D 5$ expression in sc fat. This lends some support to the view that $17 \beta-H S D 5$ expression plays a site-specific role in female obesity. 
However, the weight loss data should be interpreted with some caution; in this study we have used gluteal sc adipose tissue, which may differ from abdominal sc adipose tissue with respect to both enzymatic expression patterns and differentiation behaviour.

Interestingly, our findings with regard to $17 \beta-$ HSD 5 expression exactly mirror previous observations on the expression of the androgen receptor (AR) in human adipose tissue, describing an increased expression in om compared with sc fat and a decrease in AR expression with differentiation of preadipocytes to mature adipocytes (Dieudonne et al. 1998). Higher conversion to more active androgen in subcutaneous adipose tissue may reflect a compensatory mechanism to counteract the lower AR expression. Our findings therefore highlight the importance of understanding site-specific regulation of adipogenesis by sex steroids.

In conclusion, we have shown that human female preadipocytes are capable of active androgen generation with the conversion of androstenedione to testosterone most likely catalysed by $17 \beta-$ HSD5. We observed a siteand cell type-specific expression pattern for $17 \beta-$ HSD 5 with predominant expression in sc mature adipocytes, therefore suggesting a possible role for this enzyme in the regulation of adipocyte differentiation. We have shown that $17 \beta-$ HSD 5 expression increases across differentiation from stromal preadipocytes to mature adipocytes and that the interconversion of androstenedione and testosterone is shifted towards testosterone generation with ongoing differentiation of sc preadipocytes. In addition, we observed a positive correlation between BMI and sc 17 $\beta$-HSD5 expression and a decrease in $17 \beta-\mathrm{HSD} 5$ expression with weight loss. This supports the hypothesis that human adipose tissue may represent an intracrine source of androgen synthesis, possibly also contributing to the previously described positive correlation between circulating androgens and BMI. Further studies are warranted to explore adipose tissue-specific metabolism of sex steroids in both males and females and to elucidate the clinical significance of these findings, bearing in mind the importance of regional fat distribution for cardiovascular complications of obesity.

\section{Acknowledgements}

We would like to thank David M Smith, Carl Montague, and Kay Garnett (AstraZeneca, UK) for help with microarray analysis. We also gratefully acknowledge the support of Dr Malcolm Mattrass and the Diabetes Research Fund, University Hospital Birmingham NHS Trust. We thank the consultants and theatre staff at the Birmingham Women's Hospital, Birmingham, UK, for obtaining the fat biopsies. We thank all women who volunteered to participate in the study for their contribution.

\section{Funding}

This work was supported by the Deutsche Forschungsgemeinschaft (Research Fellowship to $M Q$, and Senior Clinical Fellowship to W A), the Medical Research Council (Research Training Fellowship to JW T, and Senior Clinical Fellowship to P M S) and by a University of Birmingham Rowbotham Bequest Research Grant (to W A).

\section{References}

Adamski J \& Jakob FJ 2001 A guide to $17 \beta$-hydroxysteroid dehydrogenases. Molecular and Cellular Endocrinology 171 1-4.

Blouin K, Richard C, Belanger C, Dupont P, Daris M, Laberge P, Luu-The V \& Tchernof A 2003 Local androgen inactivation in abdominal visceral adipose tissue. Journal of Clinical Endocrinology and Metabolism 88 5944-5950.

Bujalska IJ, Kumar S \& Stewart PM 1997 Does central obesity reflect 'Cushing's disease of the omentum'? Lancet 349 1210-1213.

Bujalska IJ, Kumar S, Hewison M \& Stewart PM 1999 Differentiation of adipose stromal cells: the roles of glucocorticoids and 11ß-hydroxysteroid dehydrogenase. Endocrinology 140 3188-3196.

Bujalska IJ, Walker EA, Hewison M \& Stewart PM 2002a A switch in dehydrogenase to reductase activity of $11 \beta$-hydroxysteroid dehydrogenase type 1 upon differentiation of human omental adipose stromal cells. Journal of Clinical Endocrinology and Metabolism 87 1205-1210.

Bujalska IJ, Walker EA, Tomlinson JW, Hewison M \& Stewart PM $2002 b 11 \beta$-Hydroxysteroid dehydrogenase type 1 in differentiating omental human preadipocytes: from de-activation to generation of cortisol. Endocrine 28 449-461.

Bumke-Vogt C, Bahr V, Diederich S, Herrmann SM, Anagnostopoulos I, Oelkers W \& Quinkler M 2002 Expression of the progesterone receptor and progesterone-metabolising enzymes in the female and male human kidney. Journal of Endocrinology 175 349-364

Corbould AM, Judd SJ \& Rodgers RJ 1998 Expression of types 1, 2, and $317 \beta$-hydroxysteroid dehydrogenase in subcutaneous abdominal and intra-abdominal adipose tissue of women. Journal of Clinical Endocrinology and Metabolism 83 187-194.

Corbould AM, Bawden MJ, Lavranos TC, Rodgers RJ \& Judd SJ 2002 The effect of obesity on the ratio of type 3 $17 \beta$-hydroxysteroid dehydrogenase mRNA to cytochrome P450 aromatase mRNA in subcutaneous abdominal and intra-abdominal adipose tissue of women. International Journal of Obesity and Related Metabolic Disorders 26 165-175.

Dieudonne MN, Pecquery R, Boumediene A, Leneveu MC \& Giudicelli Y 1998 Androgen receptors in human preadipocytes and adipocytes: regional specificities and regulation by sex steroids. American Journal of Physiology 274 C1645-C1652.

Dufort I, Rheault P, Huang X-F, Soucy P \& Luu-The V 1999 Characteristics of a highly labile human type $517 \beta$-hydroxysteroid dehydrogenase. Endocrinology 140 568-574.

Dunaif A \& Thomas A 2001 Current concepts in the polycystic ovary syndrome. Annual Review of Medicine 52 401-419.

El-Alfy M, Luu-The V, Huang X-F, Berger L, Labrie F \& Pelletier G 1999 Localization of type $517 \beta$-hydroxysteroid dehydrogenase, $3 \beta$-hydroxysteroid dehydrogenase, and androgen receptor in the human prostate by in situ hybridization and immunocytochemistry. Endocrinology 140 1481-1491.

Elting MW, Korsen TJ, Bezemer PD \& Schoemaker J 2001 Prevalence of diabetes mellitus, hypertension and cardiac complaints in a follow-up study of a Dutch PCOS population. Human 16 556-560. 
Fassnacht M, Schlenz N, Schneider SB, Wudy SA, Allolio B \& Arlt W 2003 Beyond adrenal and ovarian androgen generation: increased peripheral $5 \alpha$-reductase activity in women with polycystic ovary syndrome. Journal of Clinical Endocrinology and Metabolism $\mathbf{8 8}$ 2760-2766.

Franks S 1995 Polycystic ovary syndrome. New England Journal of Medicine 333 853-861.

Haffner SM, Valdez RA, Stern MP \& Katz MS 1993 Obesity, body fat distribution and sex hormones in men. International Journal of Obesity and Related Metabolic Disorders 17 643-649.

Hauner H, Schmid P \& Pfeiffer EF 1987 Glucocorticoids and insulin promote the differentiation of human adipocyte precursor cells into fat cells. Journal of Clinical Endocrinology and Metabolism 64 832-835.

Holte J, Bergh T, Gennarelli G \& Wide L 1994 The independent effects of polycystic ovary syndrome and obesity on serum concentrations of gonadotrophins and sex steroids in premenopausal women. Clinical Endocrinology 41 473-481.

Luu-The V 2001 Analysis and characteristics of multiple types of human $17 \beta$-hydroxysteroid dehydrogenase. Journal of Steroid Biochemistry and Molecular Biology 76 143-151.

Luu-The V, Dufort I, Pelletier G \& Labrie F 2001 Type 5 $17 \beta$-hydroxysteroid dehydrogenase: its role in the formation of androgens in women. Molecular and Cellular Endocrinology 171 $77-82$.

Mindnich R, Moller G \& Adamski J 2004 The role of $17 \beta$-hydroxysteroid dehydrogenases. Molecular and Cellular Endocrinology 218 7-20.

Penning TM, Burczynski ME, Jez JM, Hung CF, Lin HK, Ma H, Moore M, Palackal N \& Ratnam K 2000 Human $3 \alpha$-hydroxysteroid dehydrogenase isoforms (AKR1C1-AKR1C4) of the aldo-keto reductase superfamily: functional plasticity and tissue distribution reveals roles in the inactivation and formation of male and female sex hormones. Biochemical Journal 351 67-77.

Qiu W, Zhou M, Labrie F \& Lin SX 2004 Crystal structures of the multispecific $17 \beta$-hydroxysteroid dehydrogenase type 5 : critical androgen regulation in human peripheral tissues. Molecular Endocrinology 18 1798-1807.
Quinkler M, Johanssen S, Grossmann C, Bahr V, Muller M, Oelkers W \& Diederich S 1999 Progesterone metabolism in the human kidney and inhibition of $11 \beta$-hydroxysteroid dehydrogenase type 2 by progesterone and its metabolites. Journal of Clinical Endocrinology and Metabolism 84 4165-4171.

Schindler AE \& Aymar M 1975 Metabolism of ${ }^{14}$ C-dehydroepiandrosterone in female adipose tissue and venous blood. Endocrinological Experimentia 9 215-222.

Singh R, Artaza JN, Taylor WE, Gonzalez-Cadavid NF \& Bhasin S 2003 Androgens stimulate myogenic differentiation and inhibit adipogenesis in $\mathrm{C} 3 \mathrm{H} 10 \mathrm{~T} 1 / 2$ pluripotent cells through an androgen receptor-mediated pathway. Endocrinology 144 5081-5088.

Stewart PM, Shackleton CH, Beastall GH \& Edwards CR 1990 $5 \alpha$-Reductase activity in polycystic ovary syndrome. Lancet 335 431-433.

Taponen S, Martikainen H, Jarvelin MR, Laitinen J, Pouta A, Hartikainen AL, Sovio U, McCarthy MI, Franks S \& Ruokonen A 2003 Hormonal profile of women with self-reported symptoms of oligomenorrhea and/or hirsutism: Northern Finland Birth Cohort 1966 Study. Journal of Clinical Endocrinology and Metabolism 88 141-147.

Tomlinson JW, Moore JS, Clark PM, Holder G, Shakespeare L \& Stewart PM 2004 Weight loss increases 11 $\beta$-hydroxysteroid dehydrogenase type 1 expression in human adipose tissue. Journal of Clinical Endocrinology and Metabolism 89 2711-2716.

Weihua Z, Lathe R, Warner M \& Gustafsson JA 2002 An endocrine pathway in the prostate, ER $\beta$, AR, $5 \alpha$-androstane- $3 \beta, 17 \beta$-diol, and CYP7B1, regulates prostate growth. PNAS 99 13589-13594.

Williams DP, Boyden TW, Pamenter RW, Lohman TG \& Going SB 1993 Relationship of body fat percentage and fat distribution with dehydroepiandrosterone sulfate in premenopausal females. Journal of Clinical Endocrinology and Metabolism 77 80-85.

Received 9 July 2004

Accepted 22 July 2004 